\title{
Inferior rectus paresis after secondary blepharoplasty
}

\author{
EDUARDO ALFONSO, ANDREW J. LEVADA, AND JOHN T. FLYNN \\ From the Bascom Palmer Eye Institute, Department of Ophthalmology, \\ University of Miami School of Medicine, Miami, Florida, USA
}

SUMMARY A 52-year-old woman underwent a secondary cosmetic blepharoplasty for repair of residual dermatochalasis. After this procedure vertical diplopia was noted. Ultrasound examination and the findings at operation were consistent with trauma to the inferior rectus muscle. We present this as an additional complication of cosmetic blepharoplasty.

Numerous complications of blepharoplasty have been reported. They include blindness, orbital and eyelid haematoma, epiphora, ectropion, lagophthalmos, ptosis, incision complications, scar thickening, incomplete or excessive removal of orbital fat, lacrimal gland injury, exposure keratitis, and corneal ulcer. ${ }^{1-9}$ Disturbances of ocular motility are uncommon, but superior oblique palsy, ${ }^{2}$ inferior oblique injury, ${ }^{3}$ superior rectus incarceration in the wound, ${ }^{4}$ and restriction secondary to retrobulbar haemorrhage ${ }^{5}$ have been reported. We report inadvertent inferior rectus resection as an additional complication of cosmetic blepharoplasty.

\section{Case report}

A 52-year-old white woman with dermatochalasis underwent bilateral upper and lower lid cosmetic blepharoplasties and a face lifting procedure in Munich, Germany. However, one year later she was again unhappy with her appearance. In September 1980 she underwent a repeat face lifting procedure combined with bilateral upper lid blepharoplasties performed by a second surgeon in Hamburg, Germany. Five days later, on 10 October 1980, bilateral lower lid blepharoplasties were done. During a complicated dissection in which fat was noted to be adherent to tarsus and lower lid retractors, both lower conjunctival sacs were inadvertently entered. Immediately after the procedure the patient experienced vertical diplopia, worse on gaze up and to the left.

Correspondence to John T. Flynn, MD, Bascom Palmer Eye Institutc, PO Box 016880, Miami, FL 33101, USA.
The patient was examined by an ophthalmologist and observation was recommended. One year later she was examined by a second ophthalmologist in Munich. A left hypertropia of $26^{\circ}$ and exotropia of $12^{\circ}$ were found, and both inferior recti were thought to be involved. The patient could fuse only in gaze up and left. On 21 October 1981 she underwent a $5 \mathrm{~mm}$ recession of the right superior rectus muscle combined with release of conjunctival scar inferiorly, myotomy of the inferior rectus muscle, and insertion of a Teflon cap. After this procedure the ductions of the right eye were improved but diplopia persisted.

The patient was first seen at the Bascom Palmer Eye Institute four months after her eye muscle surgery. Examination revealed Snellen visual acuity of $6 / 6(20 / 20)$ in each eye. The lid fissures were equal in the primary position. Positive physical findings were limited to her ocular motility examination. At both distance and near she had a left hypertropia and exotropia in all fields of gaze. Examination of ductions showed less than $5^{\circ}$ of depression of the left eye Intorsion was preserved on down gaze. Active forced generation of the left inferior rectus was absent. The right eye showed mild limitation of up gaze. Passive ductions were normal in both eyes. After prism neutralisation of her objective angle the patient could briefly fuse targets. She could also fuse in extreme up and right gaze.

Ultrasound examination revealed widening in the region of the left inferior rectus muscle. Differentiation between intrinsic muscle widening and thickened adjacent scar tissue could not be made (Fig. 1).

On 13 July 1982 the patient underwent exploration of the left inferior rectus muscle. Only a few fibres of muscle were seen, the bulk being replaced with fibrous 


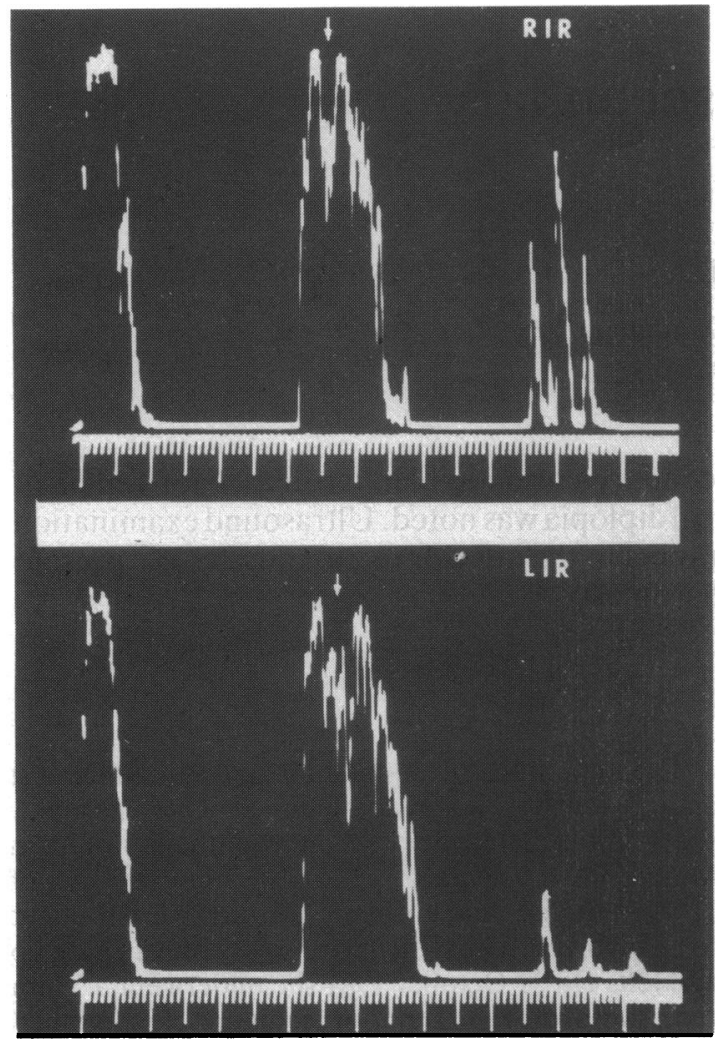

Fig. 1 Standardised A-scan echograms. Top: Arrow indicates right inferior rectus muscle (RIR). Bottom: Arrow indicates region of left inferior rectus muscle $(L I R)$.

tissue (Fig. 2). A $7.0 \mathrm{~mm}$ recession of the superior rectus muscle on an adjustable suture was performed along with transposition of the left medial and lateral recti inferiorly to the area of the inferior rectus insertion.

One month after surgery the patient had 12 prism dioptres of right hypertropia and 6 prism dioptres of exotropia at both distance and near (Fig. 3). Her field of single binocular vision performed on a Goldmann perimeter extended from $3^{\circ}$ below the primary position down to $30^{\circ}$. Horizontally it measured $70^{\circ}$ in extent. The patient achieved binocular vision with a chin up position.

\section{Discussion}

Disturbances of extraocular motility following blepharoplasty are rare, though some authors point out that temporary and permanent eye movement disorders may be more common than reports indicate. ${ }^{6}$ However, devastating symptoms can ensue. Several mechanisms of injury have been reported.
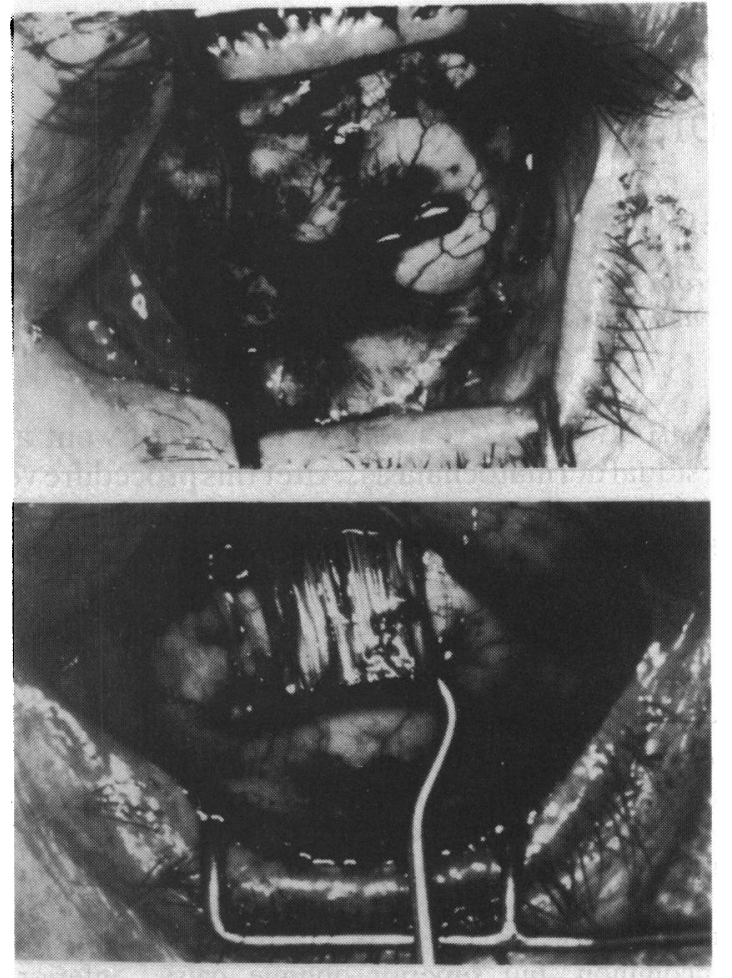

Fig. 2 Upper: Intraoperative photograph shows loss of muscle tissue, replacement by fibrous tissue, and attachments to lower lid structures in the area of the left inferior rectus muscle. Lower: Normal left superior rectus muscle.

Orbital haematoma may cause interference with the function of any of the extraocular muscles. ${ }^{7}$ Involvement of the conjunctival sac in dissection of the lid may result in symblepharon with subsequent mechanical limitation of gaze. ${ }^{4}$ Finally, careless handling of deep tissue and overzealous excision of fat during blepharoplasty are said to lead to severing, entrapment, or excision of the cyclovertical extraocular muscles-the superior rectus, inferior rectus, superior oblique, or inferior oblique. ${ }^{5}$

Reported cases of direct trauma to the extraocular muscles during lid surgery are uncommon, and we have been unable to find prior instances of damage to the inferior rectus muscle after either primary or secondary blepharoplasty. At least two cases of injury to the superior oblique muscle during primary blepharoplasty have been reported. Levine et al. ${ }^{4}$ published a case in which the superior oblique tendon, fat, orbicularis muscle, and levator aponeurosis were incarcerated within the closure of the orbital septum. Moreover, Wesley et al. ${ }^{2}$ reported a case of damage to the superior oblique tendon by electrocautery 

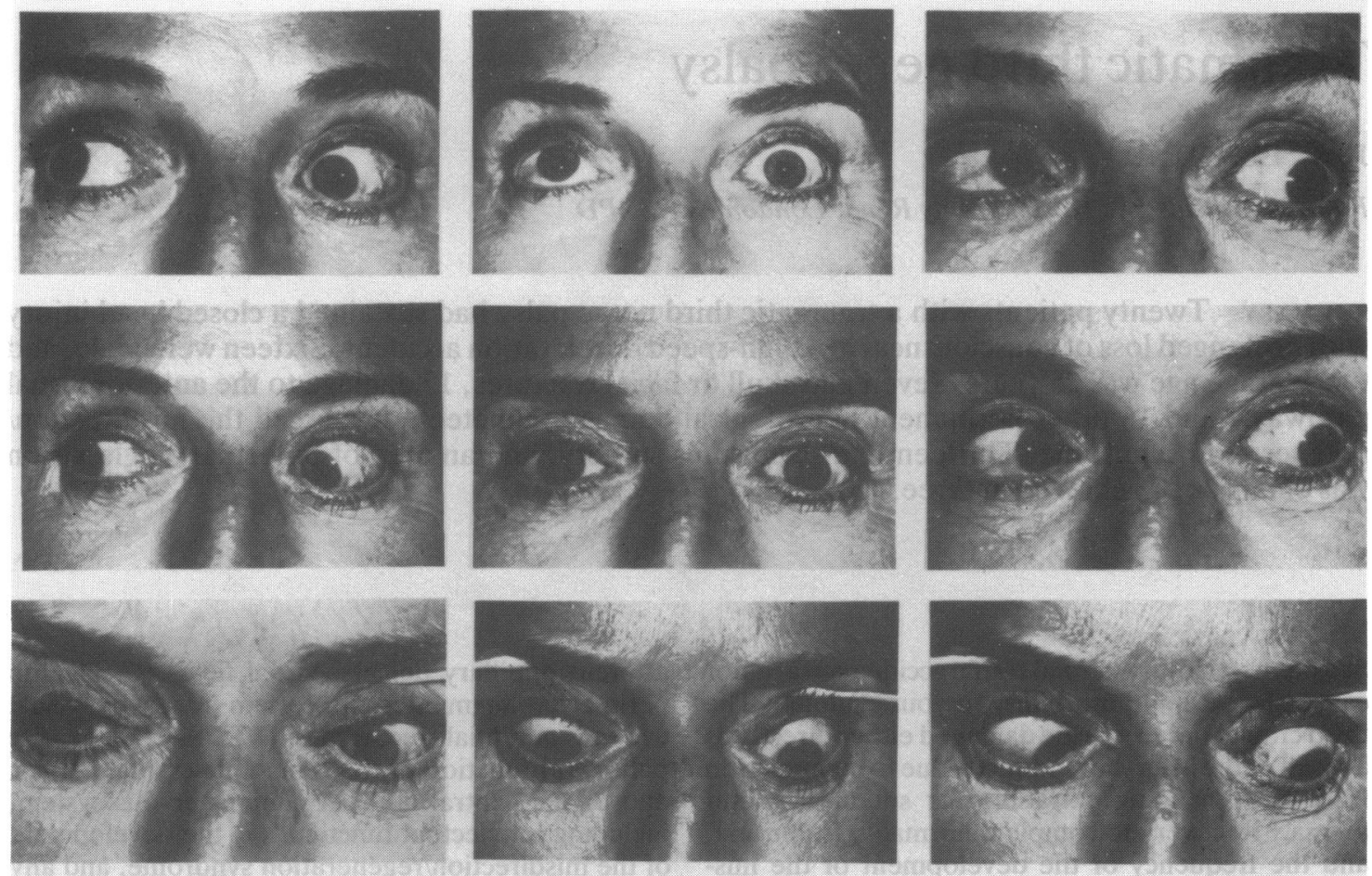

Fig. 3 Composite of eye movements one month after surgery. Note residual right hypertropia and exotropia in all fields of gaze.

during coagulation of vessels within the orbital fat near the trochlea.

Secondary blepharoplasty presents another level of complexity to the surgeon, since the anatomy of the tissues may be extensively disordered by prior surgery. Knowledge of orbital anatomy is of prime importance in helping to identify vital structures and avoid their inadvertent excision. ${ }^{6}$ Less radical removal of fat is safer and thus more desirable. $^{8}$

When extraocular muscle imbalance follows blepharoplasty, Tenzel notes that motility generally improves without surgical intervention. He recommends following diplopia fields and deferring surgery as long as improvement is seen. ${ }^{5}$

Our case developed permanent ocular misalignment following secondary bilateral lower lid blepharoplasties. This was partly due to periocular scar formation, but also due to inadvertent excision of the inferior rectus muscle. Despite extensive bilateral muscle surgery only a very small field of binocular vision has been recovered. Cosmetic blepharoplasty can have complications that will leave permanent sequelae. Thus, before it is undertaken, both the surgeon and patient should be aware of these possible complications.

Sandra Frazier Byrne performed the ultrasound examination and interpretation.

This investigation was supported in part by Research Grant EY03580-03 from the National Eye Institute, National Institutes of Health, Bethesda, Maryland.

\section{References}

1 Castanareas S. Complications of biepharoplasty. Clin Plast Surg 1978; 5: 138-65.

2 Wesley RE, Pollard ZF, McCord C. Superior oblique paresis after blepharoplasty. Plast Reconstr Surg 1980; 66: 283-7.

3 Neuhaus RW, Baylis HI. Complications of lower lid blepharoplasty. In: Rutterman AM, ed. Cosmetic oculoplastic surgery. New York: Grune and Stratton, 1980: 275-306.

4 Levine MR, Boynton J, Tenzel RR, Miller GR. Complications of blepharoplasty. Ophthalmic Surg 1975; 6: 53-7.

5 Tenzel RE. Surgical treatment of complications of cosmetic blepharoplasty. Clin Plast Surg 1978; 5: 517-23.

6 Rees TD. Cosmetic facial surgery. Philadelphia: Saunders, 1973: 51-9.

7 Smith B. Postsurgical complications of cosmetic blepharoplasty. Trans Am Acad Ophthalmol Otolaryngol 1969; 73: 1163-4.

8 Spira M. Blepharoplasty. Clin Plast Surg 1978; 5: 121-37.

9 McCord CD. Complications of upper lid blepharoplasty. In: Rutterman AM, ed. Cosmetic oculoplastic surgery. New York: Grune and Stratton, 1980: 249-74. 